\title{
O USO DAS TECNOLOGIAS DE INFORMAÇÃO E DE COMUNICAÇÃO NA PESQUISA ESCOLAR: UM ESTUDO DE CASO COM OS PNEES COM LIMITAÇÃO VISUAL
}

\author{
Eliane Lourdes da Silva Moro* \\ Lizandra Brasil Estabel** \\ Lucila Maria Costi Santarosa
}

\begin{abstract}
RESUMO: Este trabalho apresenta um estudo de caso realizado tendo como sujeitos Pessoas com Necessidades Educativas Especiais (PNEEs) com limitação visual, do Instituto Santa Luzia - Porto Alegre/RS. Aborda a Informática na Educação e o processo pedagógico da pesquisa escolar e a utilização das Tecnologias de Informação e de Comunicação (TIC's) possibilitando a inclusão social e digital.
\end{abstract}

PALAVRAS-CHAVE: Tecnologias da Informação e da Comunicação; Pessoas com Necessidades Educacionais Especiais com Limitação Visual; Pesquisa Escolar.

\begin{abstract}
This work presents a study of carried through case having as citizens People with Educative Necessities Special with visual limitation, of the Instituto Santa Luzia - Porto Alegre/RS. It approaches Computer science in the Education and the pedagogical process of the pertaining to school research and the use of the Technologies of Information and Communication making possible the social and digital inclusion.
\end{abstract}

KEYWORDS: Information and Communication Technologies; Bearers of Special Educational Needs with Visual Limitation; School Research.

\section{Introdução}

O processo da informação referente às Pessoas com Necessidades Educativas Especiais (PNEEs) com limitação visual até o início do Século XIX era baseado na oralidade, pois a inexistência de um sistema apropriado inviabilizava o seu registro. Somente em 1829, na França, surgiu o Sistema Braille que possibilitou aos cegos o acesso à leitura e à escrita. Até então, os PNEEs com limitação visual eram excluídos da cultura letrada, vivendo à margem da sociedade, dependendo exclusivamente de outras pessoas para ter acesso à informação.

No Brasil, até os anos oitenta do Século XX, somente os estados do Rio de Janeiro, São Paulo e Minas Gerais dispunham de máquinas de impressão em Braille. A política de produção do livro didático e de outros livros em Braille tinha como centro o eixo Rio-São Paulo.

Na década de 90, o surgimento dos softwares de voz ou leitores de tela possibilitou o acesso dos cegos ao ambiente informatizado, propiciando maior autonomia e independência.

\footnotetext{
* Bacharel em Biblioteconomia - FABICO/UFRGS, Licenciatura em Letras; Especialista em Informática na Educação PGIE/UFRGS; Professora do Curso de Biblioteconomia da FABICO/UFRGS; Coordenadora do Núcleo da Hora do Conto FABICO/UFRGS. E-mail: mmoro@adufrgs.ufrgs.br.

** Bacharel em Biblioteconomia - FABICO/UFRGS, ; Especialista em Informática na Educação - PGIE/UFRGS; Doutoranda em Informática na Educação - PGIE/UFRGS; Professora do Curso de Biblioteconomia da FABICO/UFRGS; Bibliotecária do Colégio Mãe de Deus e do Instituto Santa Luzia - POA/RS. E-mail: estabel@cpovo.net.

**** Professora Doutora do PPGEDU e do PGIE/UFRGS, Coordenadora Nacional da RIBIE, Coordenadora de pesquisa do NIEEUFRGS, E-mail: lucila.santarosa@ufrgs.br
} 
A informática introduziu modificações fundamentais em minha vida, ao ampliar as possibilidades de acesso à leitura, à escrita e à informação em geral. O computador com ledores de tela e sintetizadores de voz tem sido uma ferramenta indispensável em meu trabalho e fora dele. Sem este recurso, certamente, eu não teria maior autonomia e independência ou a mesma desenvoltura no desempenho de minhas atividades. $O$ efeito da informática em meu contexto de vida, talvez, possa ser comparado aos efeitos da alfabetização, letramento e escolarização de uma pessoa que, antes, era analfabeta. (SÁ, 2002).

Em 1993 surge o DOSVOX, caracterizando-se como um sistema operacional que possibilitou aos PNEEs com limitação visual, o acesso aos programas e à Internet, sem a necessidade de depender de outras pessoas. Atualmente, existem vários leitores de tela como o Virtual Vision, Jaws, entre outros, além dos ampliadores de tela, utilizados pelos portadores de baixa visão. Estes programas, segundo SANTAROSA (2004) contribuem para proporcionar aos PNEEs maior independência, qualidade de vida e inclusão social.

No período de escolaridade, os PNEEs com limitação visual necessitam do acesso às TIC's (Tecnologias de Informação e de Comunicação) com suporte nos livros ou na Internet para a construção do seu conhecimento, utilizando a leitura ou a escrita. Dentre as atividades do processo de aprendizagem e de acesso às TIC's a pesquisa escolar constitui-se uma das mais utilizadas no Ensino Fundamental e no Ensino Médio.

Este artigo apresenta como foco o uso das TIC's e o processo pedagógico da pesquisa escolar tendo como sujeitos os PNEEs com limitação visual. Realizou-se um estudo de caso com aplicação de instrumento de coleta de dados através de um questionário com perguntas abertas, semi-estruturadas, tendo como sujeitos os alunos do Instituto Santa Luzia do Ensino Fundamental e do Ensino Médio.

\section{A pesquisa escolar e os PNEEs com limitação visual}

A pesquisa escolar pode ser entendida como um processo racional e sistemático, "com método de pensamento reflexivo que requer um tratamento científico e tem como objetivo buscar respostas aos problemas sugeridos." (MORO ; ESTABEL, 2004). Os professores devem orientar e subsidiar todas as etapas para a realização da pesquisa escolar, seguindo uma metodologia para um melhor resultado da atividade, tais como: foco do tema a ser pesquisado (o que), objetivos que se pretende alcançar com a atividade (para quê), formas de busca, de elaboração e de apresentação do trabalho (como), fontes, locais ou referências (onde), data de entrega ou apresentação (quando). A pesquisa escolar

é uma das atividades que possibilita aos alunos a captação, a geração, a disseminação e a aplicação dos conhecimentos adquiridos. Para que isso ocorra, é necessário que as etapas de desenvolvimento sejam orientadas pelo professor e seguidas pelos alunos e bibliotecários, quanto à seleção do assunto, estratégias de busca e identificação das fontes, planejamento do trabalho, seleção e coleta de informações, organização das referências consultadas, organização dos registros para apresentação do trabalho (oral ou escrito). (MORO; ESTABEL, 2004). 
Por outro lado, a Sociedade da Informação preconiza a informação como um recurso prioritário e, o seu acesso, como um marco o qual insere os cidadãos na sociedade, auxiliando o exercício responsável e consciente na tomada de decisões em qualquer âmbito de ação e no exercício de seus direitos de cidadania, onde também devem estar inseridos os PNEES com limitação visual. A pesquisa escolar deve propiciar o acesso à informação, sem exclusão, através das TIC's disponibilizando materiais assistivos/adaptativos aos cegos, aos surdos, entre outros. A Internet e os livros, inclusive no sistema Braille, são caracterizados como TIC's que servem de suporte para a realização da pesquisa escolar.

\section{A pesquisa escolar realizada pelos PNEEs com limitação visual utilizando as tecnologias de informação e de comunicação: um estudo de caso}

O Instituto Santa Luzia, localizado em Porto Alegre/RS, é uma instituição educacional de caráter particular que possui alunos PNEEs com limitação visual e alunos com visão normal. A escola vivencia uma Educação Inclusiva, onde alunos com visão normal e com limitação visual compartilham os mesmos ambientes de aprendizagem: sala de aula, laboratório de informática, biblioteca, entre outros. Segundo Vygotsky (1984) construir conhecimentos implica numa ação partilhada, já que é através dos outros que as relações entre sujeito e objeto são estabelecidas. Santarosa (1997) afirma que o processo pedagógico deve focalizar a construção de conhecimento associado ao processo de apropriação dos recursos tecnológicos tendo o aporte de aprender a se comunicar, aprender a aprender, aprender com o outro e a prender a ser.

O PROINESP (Projeto de Informática para Educação Especial), da Secretaria de Educação Especial, do Ministério da Educação, contemplou o Instituto, em 2000, com um laboratório equipado com 13 computadores, adaptado para os PNEEs com limitação visual. Desde então os alunos passaram a utilizar a informática como ferramenta de acesso à informação e de construção do conhecimento.

Os alunos PNEEs com limitação visual do Ensino Fundamental ( $5^{\mathrm{a}}$ a $8^{\mathrm{a}}$ séries $)$ e do Ensino Médio estudam no período da manhã. À tarde, freqüentam atividades de reforço pedagógico com enfoque nos temas de casa, da pesquisa escolar, entre outros. Desta forma, o aluno com limitação visual é acompanhado na realização de suas atividades extra-classe, onde um professor auxilia nas dificuldades individuais que se apresentam e realiza a transcrição do Braille quando necessário. Além do reforço, os PNEEs com limitação visual participam de atividades físicas, de mobilidade, aulas de Informática entre outros.

A aplicação deste trabalho teve como população alvo um total de 7 (sete) alunos: 4 (quatro) alunos do Ensino Fundamental ( $5^{\mathrm{a}}$ a $8^{\mathrm{a}}$ séries) e 3 (três) alunos do Ensino Médio. Apesar das diferentes seriações que os alunos estão cursando, a faixa etária é aproximada, variando dos 16 aos 19 anos, podendo-se afirmar que os sujeitos são adolescentes em período de escolaridade, convivendo no mesmo ambiente institucional, tendo como diagnóstico a cegueira total.

\section{Compilação dos resultados da aplicação do instrumento do estudo de caso}

A compilação dos resultados do questionário aplicado no estudo de caso teve como foco a pesquisa escolar e os procedimentos para a sua execução pelos PNEEs com 
limitação visual. O instrumento de avaliação envolvia dez questões, abordando alguns aspectos da pesquisa escolar e o uso da Internet e de outras fontes para a realização da mesma. A aplicação do questionário foi realizada oralmente, uma vez que as questões não foram transcritas para o alfabeto Braille. Cada sujeito do foco deste trabalho, participou individualmente da realização da atividade, tendo como ambiente a biblioteca da escola. Para preservar a identidade dos sujeitos participantes deste instrumento, foram utilizadas as nomenclaturas de Aluna 1, Aluna 2, Aluno 3, Aluno 4, Aluno 5, Aluna 6 e Aluno 7.

A $1^{\text {a }}$ questão elaborada para os alunos foi a seguinte: "Quando o professor solicita uma pesquisa, qual é a primeira coisa que você faz?".

Aluna 1: Dirige-se para a sala de atendimento, após pegar o livro em Braille na biblioteca. Elabora resumos. Prefere e usa a Internet, embora a página seja difícil de acessar e as gravuras o programa não leia corretamente. Acessibilidade das páginas.

Aluna 2: Solicita auxílio de outras pessoas (professor de reforço ou colegas). Procura e retira o livro em Braille na Biblioteca. Prefere o livro à Internet.

Aluno 3: Vai direto à Internet.

Aluno 4: Vai direto à biblioteca da escola.

Aluno 5: Pesquisa em livros em Braille e elabora um resumo. Procura material impresso em tinta e alguém lê o conteúdo escrito.

Aluna 6: Vai na sala de estudo, solicita auxílio, após retirar o livro em Braille na biblioteca da escola. Se não encontra o assunto nos livros em Braille, usa a Internet.

Aluno 7: Solicita livro em Braille na biblioteca da escola e utiliza os indicados que contenham o assunto procurado. Não procura em biblioteca de escola pública pois a mesma "tem poucas "coisas" em Braille".

Ao receber a atividade proposta pelo professor, os alunos de forma direta ou indireta, procuram auxílio para a realização da pesquisa, através do professor de reforço, do professor de informática e da equipe que atende na biblioteca, seja através da Internet, seja através do acervo em Braille. A biblioteca da escola é bastante requisitada através do acervo em Braille que contenha os assuntos procurados. A busca pelo livro é bastante significativa nesta questão, percebendo-se o papel importante que a biblioteca exerce na escola através das TIC's. Outra dificuldade que os PNEEs com limitação visual enfrentam é onde e como buscar os assuntos determinados pelos professores, os quais, na maioria das vezes, não são indicadas as fontes para consulta. Pode-se constatar através das respostas na questão seguinte.

A $2^{\mathrm{a}}$ questão a ser respondida pelos entrevistados referia-se ao procedimento do professor no momento de solicitar a atividade da pesquisa escolar, perguntando se "o professor indica onde e como encontrar o assunto para a pesquisa". As respostas foram:

Aluna 1: Em geral, os professores não indicam. Algumas coisas têm no livro didático.

Aluna 2: A maioria dos professores não fornece maiores informações. O professor de Português é que mais orienta. Assunto que mais gosta de Pesquisar: Filosofia e Sociologia.

Aluno 3: Geralmente não. Ele dá o assunto e manda me virar.

Aluno 4: Muitas vezes sim. Não indica a bibliografia. Só onde encontrar.

Aluno 5: Normalmente não.

Aluna 6: É difícil. A maioria das vezes pergunta ao professor onde buscar.

Aluno 7: Alguns sim, outros não. Indicam a Internet ou livro. 
Percebe-se que o professor, ao solicitar a pesquisa escolar não indica nem fontes, nem local e nem referências para o aluno localizar os assuntos solicitados, dificultando bastante o processo de busca.

A questão de número 3 pergunta se "o professor indica/orienta o trabalho fornecendo roteiro para elaboração do mesmo". Apresentava-se as alternativas "sim" ou "não". As respostas foram as seguintes:

Aluna 1: Sim. Quando o professor fornece roteiro indicando as partes do trabalho que ele quer que apresente: capa, sumário, introdução... Fica mais fácil realizar o trabalho.

Aluna 2: Sim. Prefere o trabalho orientado e utilizando a metodologia científica.

Aluno 3: Sim. Fornece questões que devem ser respondidas. Segue a ABNT.

Aluno 4: Sim.

Aluno 5: Depende.

Aluna 6: Sim. Explicam as partes do trabalho mas não fornecem as fontes.

Aluno 7: Sim. Tudo explicado.

Para os alunos construírem novos conhecimentos através da pesquisa escolar, é importante a orientação dos professores seguindo uma metodologia científica em todas as etapas da realização da mesma. Os professores devem orientar quanto ao tema a ser abordado, aos objetivos a serem alcançados, as estratégias de busca da informação, a forma de elaboração e de apresentação do trabalho, as fontes, locais ou referências, ao prazo de entrega ou de apresentação. Da mesma forma, uma orientação das partes constitutivas da apresentação impressa do trabalho é importante para os alunos, como a elaboração da capa, sumário, introdução, desenvolvimento, conclusão(sões), referências segundo as normas da ABNT(Associação Brasileira de Normas Técnicas).

A questão 4, perguntava se "solicitavam auxílio a colegas ou a outras pessoas para a realização da pesquisa escolar." O objetivo era verificar a dependência ou a autonomia para a realização da pesquisa escolar. As respostas obtidas foram as seguintes:

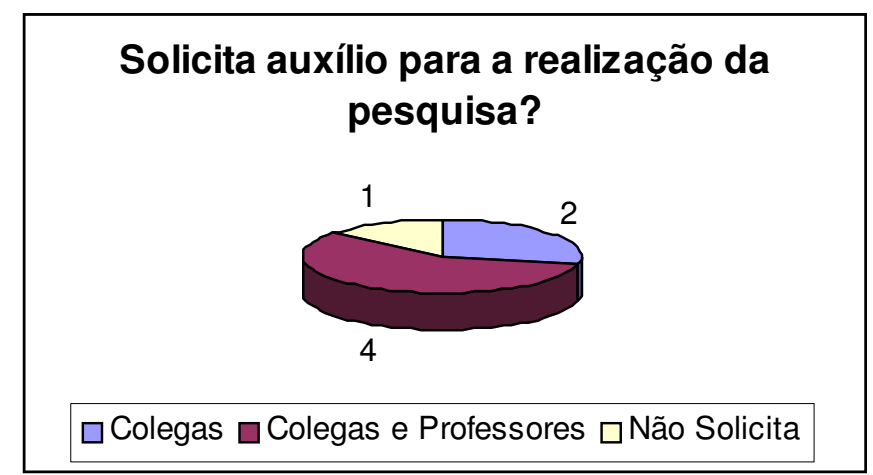

Quadro 1: Auxílio para a realização da pesquisa escolar

A maioria dos sujeitos solicita auxílio no processo de busca da informação. $\mathrm{O}$ uso da Internet propicia a autonomia na realização da pesquisa, uma vez encontrado o assunto, os procedimentos de leitura, elaboração do texto e organização do trabalho é feito independentemente do auxílio de terceiros. Percebe-se a importância do processo pedagógico promover o compartilhamento de experiências, idéias e conhecimentos 
entre os alunos e professores e entre os alunos, em uma concepção interacionista de aprendizagem, onde o professor é o mediador do processo, o aluno o interagente e o conhecimento o resultado da ação e das interações entre os sujeitos. Segundo Santarosa (1997), a aprendizagem, em qualquer ambiente, é um processo ativo, cujo desenvolvimento não pode ser ensinado, só aprendido. Nesse processo, cada homem transforma e sofre os efeitos dessa transformação, transformando-se.

A $5^{\text {a }}$ pergunta referia-se à disponibilidade de acesso aos materiais de consulta e aos locais onde eram encontrados. Oferecia três locais podendo ser escolhidas as três alternativas e ainda, se em outro local, dever-se-ia indicá-lo. As respostas foram as seguintes:

\section{( 4 ) em casa ( 5 ) na biblioteca ( 4 ) na escola ( 0 )em outro local.}

Observação: Todos os que realizam as atividades em casa, utilizam a Internet.

Na questão de número 6, foi perguntado se eles preferiam "ouvir ou ler" para realizar a pesquisa e o porquê. Obteve-se os seguintes dados:

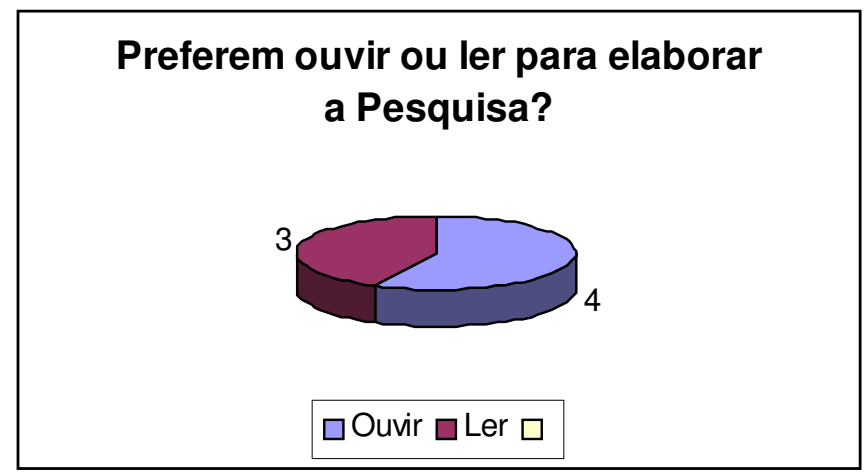

\section{Quadro 2: Preferem ouvir ou ler para elaboração da pesquisa escolar}

A relação dos PNEEs com limitação visual, com a leitura e com a escrita se estabelece no período escolar, pois no período anterior o processo de comunicação é fundamentado na oralidade. Por outro lado, no ambiente familiar, os alunos não têm acesso ao acervo em Braille, ao contrário, no ambiente da escola, o acervo está disponível na biblioteca escolar. A agilidade tátil nem sempre acompanha o processo do pensamento lógico, privando, muitas vezes, de imaginar...criar...fantasiar.

$\mathrm{Na} 7^{\mathrm{a}}$ questão foi perguntado quais eram os procedimentos utilizados para buscar e encontrar os assuntos na Internet. Os alunos que utilizam esporadicamente a Internet não foram muito enfáticos em suas respostas. Aqueles que utilizam a Internet com maior freqüência, não titubearam e responderam de imediato e com firmeza:

Aluna 1: Utiliza o "Google" ou o "Terra" para acessar as informações. Coloca o assunto e pede auxílio a quem estiver próximo, para solicitar "páginas em português". O procedimento é acessar as páginas, selecionar, copiar.

Aluna 2: Não utiliza com frequiência a Internet. Quando usa, pede auxílio ao professor de informática. Usa o "Google" ou o "Terra". O professor que auxilia é paciente ao ajudá-la. 
Aluno 3: "Vou no site de trabalhos prontos e baixo. Alguns sites como o "Zé Moleza" apresentam os trabalhos prontos". Só não faz esse procedimento quando a pesquisa escolar tratar de assuntos ou disciplinas que ele gosta, dentre elas Literatura e História. Nesse caso, ele busca e formula o trabalho, compara com outros.

Aluno 4: "Entro no site "Google" ou "Cadê" e coloco o assunto." Não procura outros assuntos, o primeiro que encontra é o selecionado para o trabalho.

Aluno 5: Sempre procura no "Cadê". O critério de escolha é o que estiver mais resumido.

Aluna 6: Entra no "Cadê". Procura no computador, pois é mais resumido que nos livros.

Aluno 7: Acessa o site "Google", com o título do trabalho. Abre cada página para "ler". Navega em várias páginas antes de definir a escrita do trabalho.

A pergunta de número 8 pretendia verificar se os alunos, ao encontrar o assunto procurado, copiavam como se apresenta o texto ou re-elaboravam as informações apresentadas através da escrita com suas próprias palavras. As respostas foram:

\section{Copia ou re-elabora as informações encontradas?}

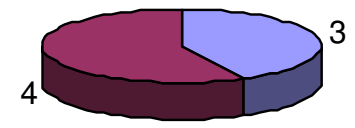

Copia $\square$ Re-elabora $\square$

\section{Quadro 3: Copia ou re-elabora as informações encontradas?}

"O conhecimento nasce toda vez que o ser humano se apropria do seu pensar". (BECKER, 2000). O processo de avaliação do professor deve estar em harmonia com o ambiente de aprendizagem e com o processo construtivo do aluno. $\mathrm{O}$ professor exerce papel de orientador, questionando, sugerindo, aproveitando-se do saber do aluno para melhor conduzi-lo na construção do conhecimento. Por isso, a importância de estimular a re-elaboração dos textos lidos ao invés da cópia que o aluno realiza, entrega ao professor e este atribui uma avaliação.

Geralmente, ao solicitar a apresentação do trabalho, o professor indica a forma: escrito ou oral. No caso do trabalho escrito, o professor não indica se o mesmo deverá ser entregue à tinta ou em Braille. Por isso foi perguntado, na questão 9, de que forma era apresentado o trabalho para o professor. As respostas foram as seguintes:

Aluna 1: Entrega do trabalho em Braille. Em alguns casos a entrega é à tinta.

Aluna 2: A entrega do trabalho é em Braille. Quando o trabalho é realizado em grupo, a parte individual é realizada em Braille, entregue para o grupo e o mesmo é transcrito para o trabalho do grupo na forma "normal" de apresentação.

Aluno 3: A entrega do trabalho é à tinta.

Aluno 4: Entrega do trabalho em Braille.

Aluno 5: Entrega do trabalho em Braille ou manda para a transcrição.

Aluna 6: Entrega do trabalho em Braille.

Aluno 7: Entrega do trabalho em Braille e à tinta, para facilitar a correção do professor. 
Os professores aceitam os trabalhos na forma impressa que o aluno preferir apresentar, uma vez que todos são qualificados para decodificar o sistema Braille.

Na última e décima questão foi perguntado se, geralmente, ficavam satisfeitos com a pesquisa realizada. Se a resposta afirmativa ou negativa deveria ser justificada. Chegou-se às seguintes respostas:

Aluna 1: "Depende quando o assunto é importante. Dependendo das disciplinas, o vocabulário dificulta para a memorização e apreensão, principalmente quando tem de apresentar o trabalho oralmente. Para apresentar um trabalho de Filosofia é mais fácil do que apresentar um trabalho de Biologia pelo emprego do vocabulário.

Aluna 2: "Quando a pesquisa fica completa, compreensível para o professor avaliar, ficou boa, eu me sinto satisfeita".

Aluno 3: Sim. Fica satisfeito quando encontra os assuntos que procura. Quando não é interessante o assunto e realiza a pesquisa só pela nota, não fica satisfeito.

Aluno 4: "Eu não faço por prazer, mas por obrigação. Em geral o trabalho fica bom."

Aluno 5: Sim. Quase sempre.

Aluna 6: "Quando faço no computador não fico muito satisfeita. No livro sim tenho mais autonomia".

Aluno 7: "Às vezes sim, às vezes não. Depende do assunto." "Perdi meu tempo quando já sabia sobre o assunto". Sente-se satisfeito quando vai pesquisar e o autor escreveu sobre aquilo que ele já tinha feito no trabalho sem buscar em outro lugar. Sente-se mais satisfeito quando pesquisa seus assuntos preferidos: Ciências, Universo, Plantas e Curas, poemas românticos...

\section{Considerações finais}

As TIC's apresentaram novas formas de buscas e multiplicaram as fontes, mas o processo da sua realização continua inalterado, mesmo mudando os sujeitos: PNEEs com limitação visual e alunos com visão normal. A partir dos dados coletados e analisados, observou-se que a Internet tem influência na pesquisa escolar, na medida em que facilita o acesso à informação. No entanto, também facilita a cópia tornando muitas vezes o texto encontrado na rede propriedade autoral do sujeito que realizou a pesquisa.

Ao realizar a pesquisa escolar, é importante que os PNEEs com limitação visual adquiriam a competência de consultar em diferentes fontes (pessoais, bibliográficas, tecnológicas), que localizem os assuntos procurados independentemente, que identifiquem as idéias principais do texto e consigam compreendê-las e interpretá-las, que relacionem assuntos correlatos, que elaborem sínteses e conclusões a partir dos textos lidos e que referenciem as fontes consultadas, enfim, que sejam os atores principais na construção do seu conhecimento.

O acesso às TIC's propicia aos PNEEs com limitação visual estarem inseridos, como iguais, em um mundo de tantas diferenças, onde a inclusão social e digital , através do processo da pesquisa escolar pode possibilitar o compartilhamento e a cooperação entre os sujeitos ativos do processo de aprender: professores, alunos PNEEs com limitação visual e alunos com visão normal.

\section{Referências}


Becker, F.(2000). Docência e Conhecimento. Caxias do Sul, UCS, 26 de abril 2000. $<$ Palestra na UCS-RS no Seminário de Atualização Didático-Pedagógica>.

Belarmino, J.(2004). As Novas Tecnologias e a "Desbrailização": mito ou realidade?. Disponível em: http://intervox.nce.ufrj.br/ joana/textos/desbrailiz.htm. Acesso em: 30 mai.

Estabel, L. B. (2002). A Internet Modificando a Vida dos Portadores de Limitação Visual através do uso de Listas de Discussão. Porto Alegre: PGIE/UFRGS. (Monografia)

Moro, E. L. S.; Dias, J.; Estabel, L. \& Carneiro, M.L.F. (2002). As Novas Tecnologias da Informação e da Comunicação e a Pesquisa Escolar. Anais do XXII Congresso da Sociedade Brasileira de Computação, Florianópolis, v.5, 45-54.

Moro, E. L. S. \& Estabel, L. B. (2004). Um Novo Paradigma na Sociedade da Informação: A Pesquisa Escolar Propiciando a Integração dos Atores - Aprendizes, Professores e Bibliotecários - Irradiando o Benefício Coletivo e a Cidadania. Revista Novas Tecnologias na Educação. Disponível em: http://www.cinted.ufrgs.br/renote/mar2004/index.html .

Sá, E. D. de. (2004). Lista VV [mensagem pessoal]. Mensagem recebida por <estabel@cpovo.net> em 14 de nov. Acesso em: 26 mai.

Santarosa, L. M. C. (2004). Ambientes de Aprendizagem Virtuais/Digitais para o Desenvolvimento e a Inclusão de Pessoas com Necessidades Educativas Especiais. Disponível: http://libra.niee.ufrgs.br/ proinesp/amb_dig/index.html. Acesso em:30 mai.

. (1997). Escola Virtual para Educação especial: ambientes de aprendizagem telemáticos cooperativos como alternativa de desenvolvimento. Informática Educativa/UNIANDES/LIDIE. Colômbia, v.10, n.1, p.115-138.

Vygotsky, L. S. (1987). Pensamento e Linguagem. São Paulo : Martins Fontes. 